Library, N.W. Bldg

DEC 161964

NBS

Eechnical Note

\title{
DISCLOSURES ON VARIOUS SUBJECTS
}

A Plumbing Vent Manifold,

A Micro-Adjuster,

A Glass Joint or Stopcock, and

A Miniature Puller

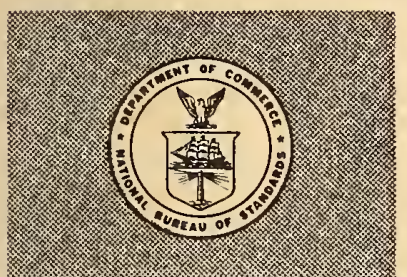

U. S. DEPARTMENT OF COMMERCE

NATIONAL BUREAU OF STANDARDS 


\section{THE NATIONAL BUREAU OF STANDARDS}

The National Bureau of Standards is a principal focal point in the Federal Government for assuring maximum application of the physical and engineering sciences to the advancement of technology in industry and commerce. Its responsibilities include development and maintenance of the national standards of measurement, and the provisions of means for making measurements consistent with those standards; determination of physical constants and properties of materials; development of methods for testing materials, mechanisms, and structures, and making such tests as may be necessary, particularly for government agencies; cooperation in the establishment of standard practices for incorporation in codes and specifications; advisory service to government agencies on scientific and technical problems; invention and development of devices to serve special needs of the Government; assistance to industry, business, and consumers in the development and acceptance of commercial standards and simplified trade practice recommendations; administration of programs in cooperation with United States business groups and standards organizations for the development of international standards of practice; and maintenance of a clearinghouse for the collection and dissemination of scientific, technical, and engineering information. The scope of the Bureau's activities is suggested in the following listing of its four Institutes and their organizational units.

Institute for Basic Standards. Electricity. Metrology. Heat. Radiation Physics. Mechanics. Applied Mathematics. Atomic Physics. Physical Chemistry. Laboratory Astrophysics. ${ }^{*}$ Radio Standards Laboratory: Radio Standards Physics; Radio Standards Engineering. * " Office of Standard Reference Data.

Institute for Materials Research. Analytical Chemistry. Polymers. Metallurgy. Inorganic Materials. Reactor Radiations. Cryogenics. ${ }^{*}$ Office of Standard Reference Materials.

Central Radio Propagation Laboratory.** Ionosphere Research and Propagation. Troposphere and Space Telecommunications. Radio Systems. Upper Atmosphere and Space Physics.

Institute for Applied Technology. Textiles and Apparel Technology Center. Building Research. Industrial Equipment. Information Technology. Performance Test Development. Instrumentation. Transport .Systems. Office of Technical Services. Office of Weights and Measures. Office of Engineering Standards. Office of Industrial Services.

\footnotetext{
- NBS Group, Joint Institute for Laboratory Astrophysics at the University of Colorado.
}

* Located at Boulder, Colorado. 


\title{
NATIONAL BUREAU OF STANDARDS Technical Note 253
}

ISSUED NOVEMBER 30, 1964

\section{DISCLOSURES ON VARIOUS SUBJECTS}

\author{
A Plumbing Vent Manifold, \\ A Micro-Adjuster, \\ A Glass Joint or Stopcock, and \\ A Miniature Puller
}

David Robbins, Editor

\begin{abstract}
NBS Technical Notes are designed to supplement the Bureau's regular publications program. They provide a means for making available scientific data that are of transient or limited interest. Technical Notes may be listed or referred to in the open literature.
\end{abstract}



TABLE OF CONTENTS

Title

Author

Page

A Vent Manifold for a

R. W. Beausoliel

1

Plumbing System

National Bureau of Standards

Washington, D.C. 20234

A Micro-Adjuster Providing

Purely Rectilinear Motion

N. V. Frederick

2

National Bureau of Standards

Boulder, Colorado 80310

A Glass Joint or Stopcock Preventing Capillary

Action

R. Gary

National Bureau of Standards

Washington, D. C. 20234

Miniature Gear, Flange

and Bearing Puller

C. B. Haegele

7

U.S. Weather Bureau

Washington, D.C. 20235 
This Note presents four devices embodying interesting and unusual solutions to problems prevalent in their respective arts. These devices, developed at the National Bureau of Standards and the U.S. Weather Bureau, comprise a vent manifold for a plumbing system; a micro-adjuster providing purely rectilinear motion; a miniature gear, flange and bearing puller, and a glass joint or stopcock preventing capillary action.

Tech. Note No. 253, November 30, 1964 
A VENT MANIFOLD FOR A PLUMBING SYSTEM

Robert W. Beausoliel

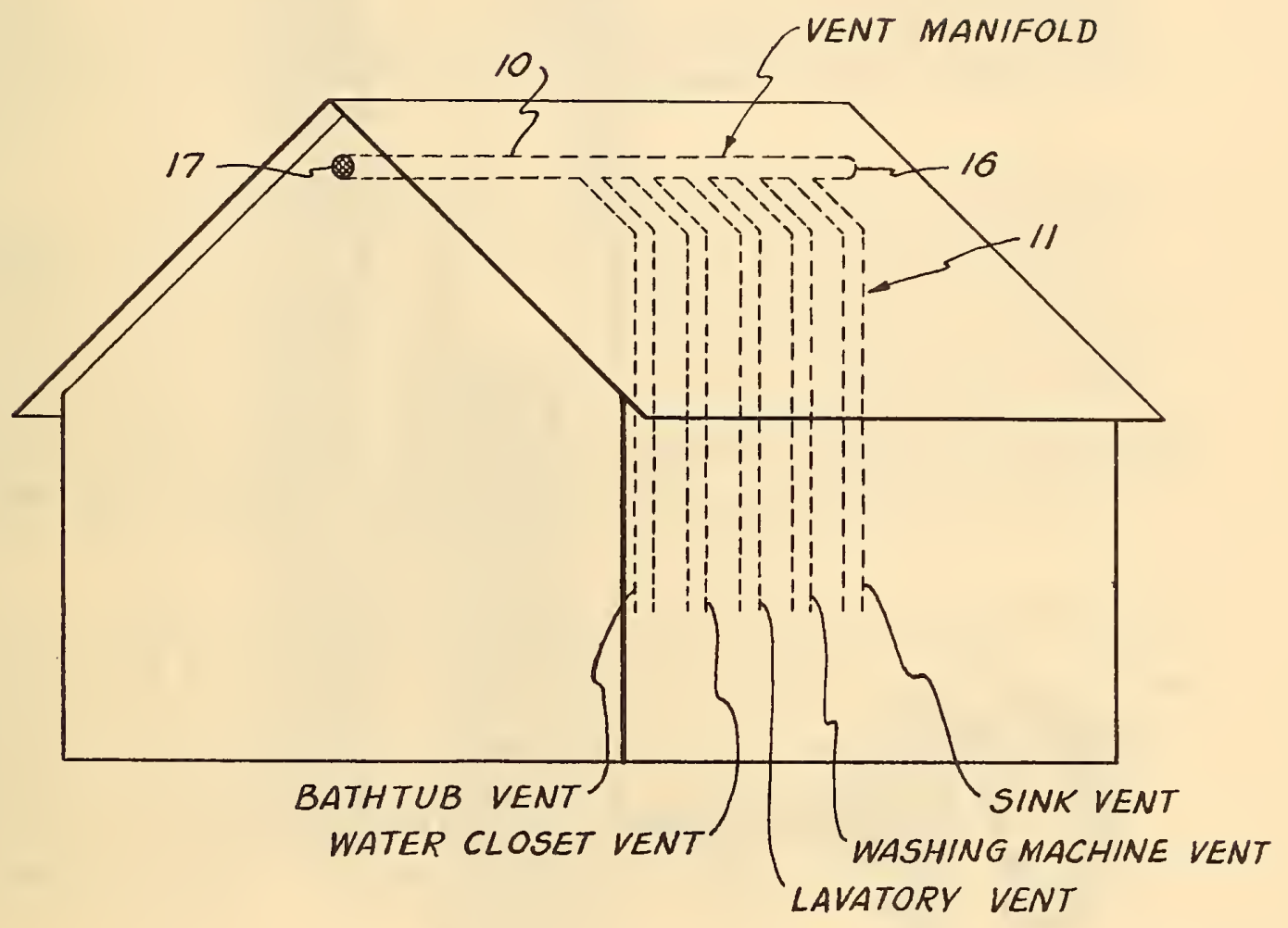

Normally, a number of the vents employed in a plumbing system penetrate the roof of the bullding, and these penetrations greatly increase the possibility of roof leakage and add to the cost.

In the present arrangement, manifold 10 penetrates the gable where there is less chance of leakage, and the various fixture vents 11 tie into the manifold. The manifold is sealed at one end 16 and may have a screen 17 at the other end. The vents and manifold may be constructed of various materlals that give suitable performance under the service to which vent systems are subjected.

Tech. Note No. 253, November 30, 1964 
A MICRO-ADJUSTER PROVIDING PURELY RECTILINEAR MOTION Nolan V. Frederick

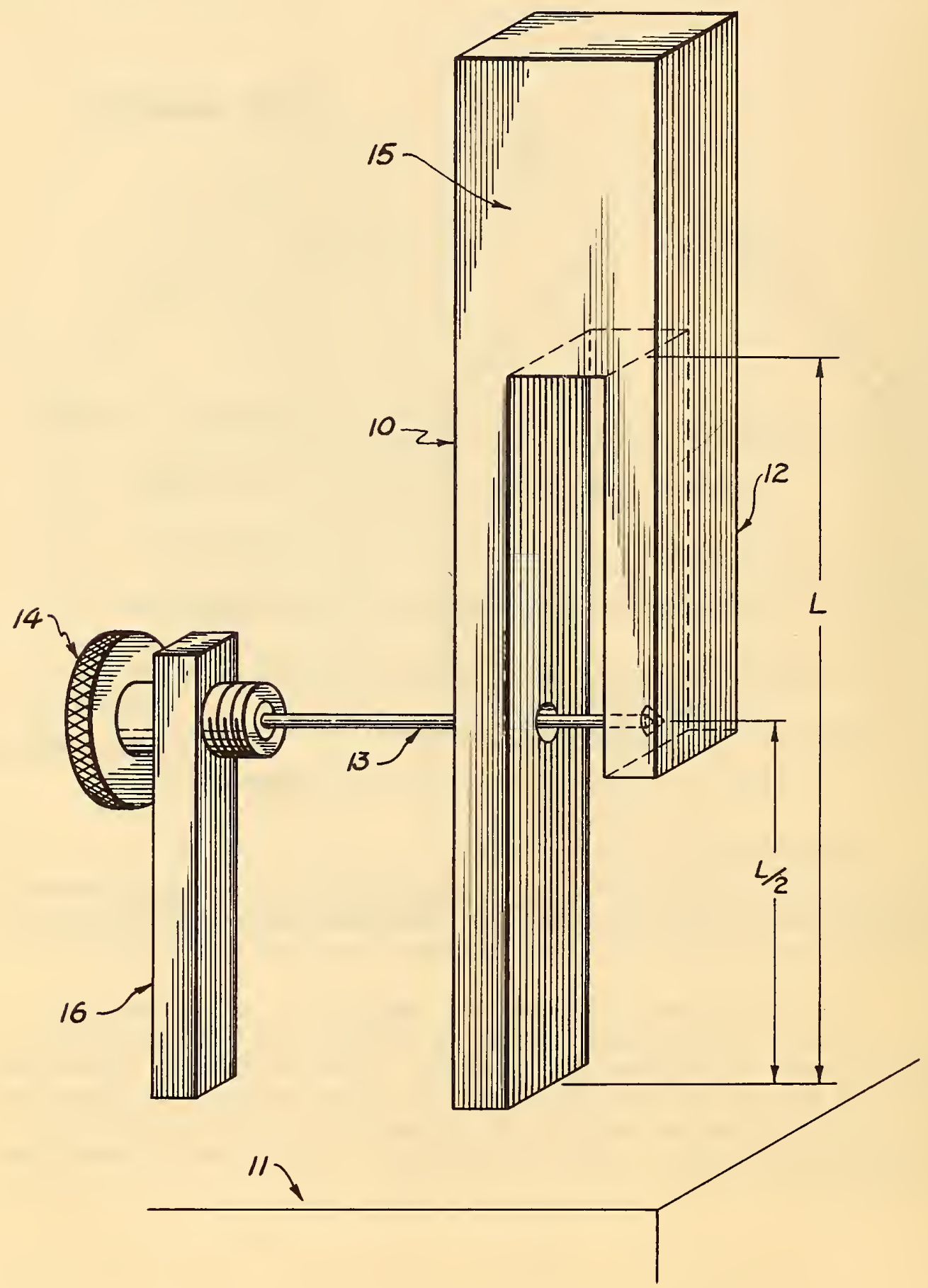

Tech. Note No. 253, November 30, 1964 
Nolan V. Frederick

This is a micro-adjuster that will bring about purely rectilinear motion of an element. The element could be a mirror employed in optical interferometry, a suspension for a galvanometer type instrument, or any other device required to undergo small translatory motions without rotation.

The major component of the micro-adjuster resembles a tuning fork with one leg shorter than its partner. The free end of the longer leg 10 is rigidly fastened to a reference plane 11 , a block of solid matter, such that the vertical axis of the leg is normal to the reference plane. The fastening means is selected so as not to interfere with the normal elastic behaviour of legs 10 and 12 as they extend above the reference plane. The shorter leg 12 must not come into contact with the reference plane or any other object except kinematic connector 13, which is controlled by means of screw 14, positioned on support post 16 .

Connector 13 exerts a force on leg 12 in a plane parallel to the reference plane 11 and in a plane passing through a vertical axis of both legs and half-way up the length $L$ of leg 10 . Since the legs are free to flex and bend under the influence of this force, it can be shown from elementary theory of bending of elastic materials that part 15, above the confluence of the two legs, will move in a translatory fashion without rotation. The cross sections of the legs may be changed relative to each other to change the ratio of motions of the screw and part 15 .

Tech. Note No. 253, November 30, 1964 
A GLASS JOINT OR STOPCOCK PREVENTING CAPILLARY ACTION Robert Gary

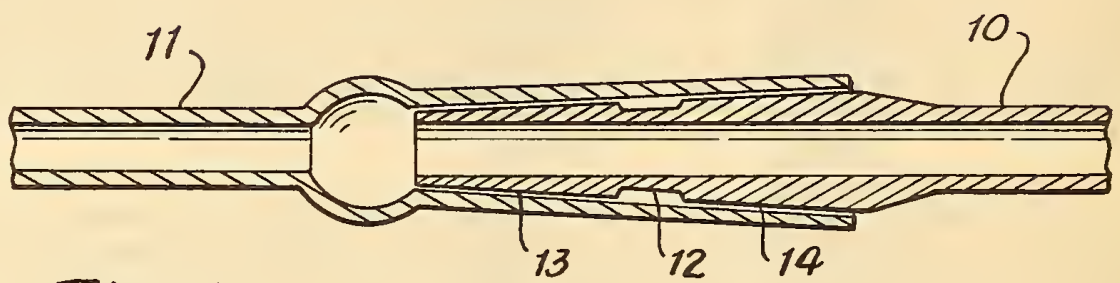

Fig. 1
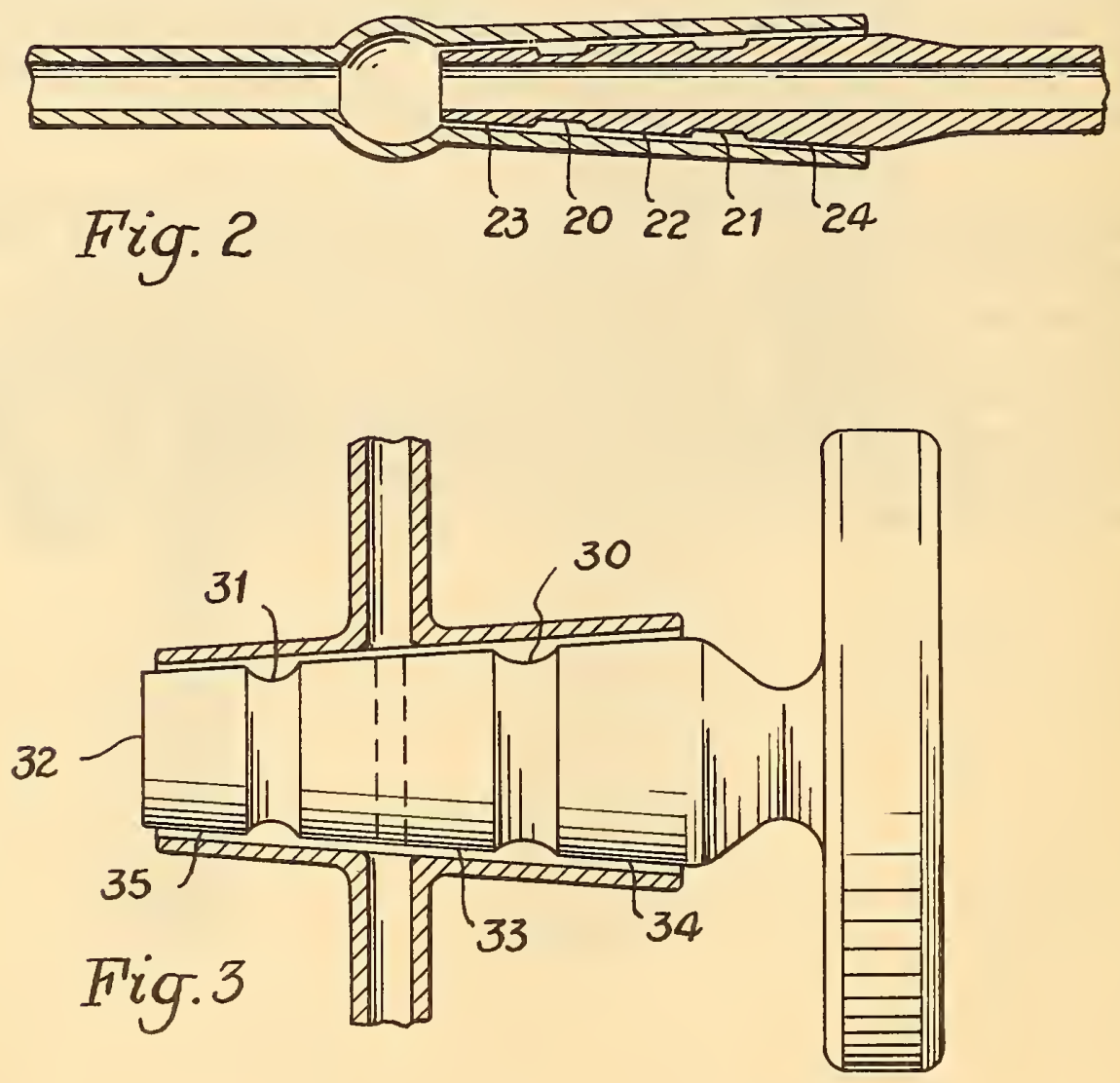

Tech. Note No. 253, November 30, 1964 
A GLASS JOINT OR STOPCOCK PREVENTING CAPILLARY ACTION

Robert Gary

Ground glass joints in common use today present two notorious problems: the close fit of the inner and outer members of the joints causes liquids to advance through the joints by capillary action, and the joints do not of themselves form a vacuum-tight seal.

The essential element of this disclosure is a groove positioned in either the inner or outer member of a joint or stopcock in the manner illustrated in the figures.

Fig. 1 shows the inner member 10 and the outer member 11 of a tapered, ground glass joint with a groove 12 in the outer surface of the inner member. The exact dimensions of the groove are not essential, so long as the groove is sufficiently wide and deep to provide two functions. First, it prevents liquids from advancing by capillary action across the joint through the narrow space between the inner and outer members 10 and 11 . Second, the groove permits the use of grease, if destred, without danger of contaminating those materials which may come in contact with the greased joint and without permitting the grease to be dissolved away by solvents. The grease 1s applied either to portion 13 only or to portion 14 only, as desired. The ungreased portion, together with groove 12, serves to prevent the access of materials, such as pure reagents or solvents, to the greased portion of the joint.

In Fig. 2, grooves 20 and 21 are similar to groove 12 and serve a similar function. If it is desired to use grease, it may be applied to the center section 22 only. The greased portion would then be protected from attack by materials advancing from either or both ends of the joint. Alternatively, grease could be applied to section 23 or to section 24 only. In this case, the greased portion would be doubly protected from attack by materials advancing from one direction only.

The teachings of the present disclosure may be applied to a stopcock, as shown in Fig. 3. Here grooves 30 and 31 , positioned in plug 32, separate the ungreased portion 33 from portions 34 and 35 , which may or may not be greased as desired. The use of two grooves on each side of 33 would provide even more protection agalnst contamination by grease of materials passing through the stopcock.

Tech. Note No. 253, November 30, 1964 
The first stopcocks, made in early 1961, were fabricated by grinding the grooves into commerclally avallable, ground glass plugs, but this does not necessarily represent the best method of fabrication.

Tech. Note No. 253, November 3U, 1964 
MINIATURE GEAR, FLANGE AND BEARING PULLER

Charles B. Haegele

\section{Fig. 1}

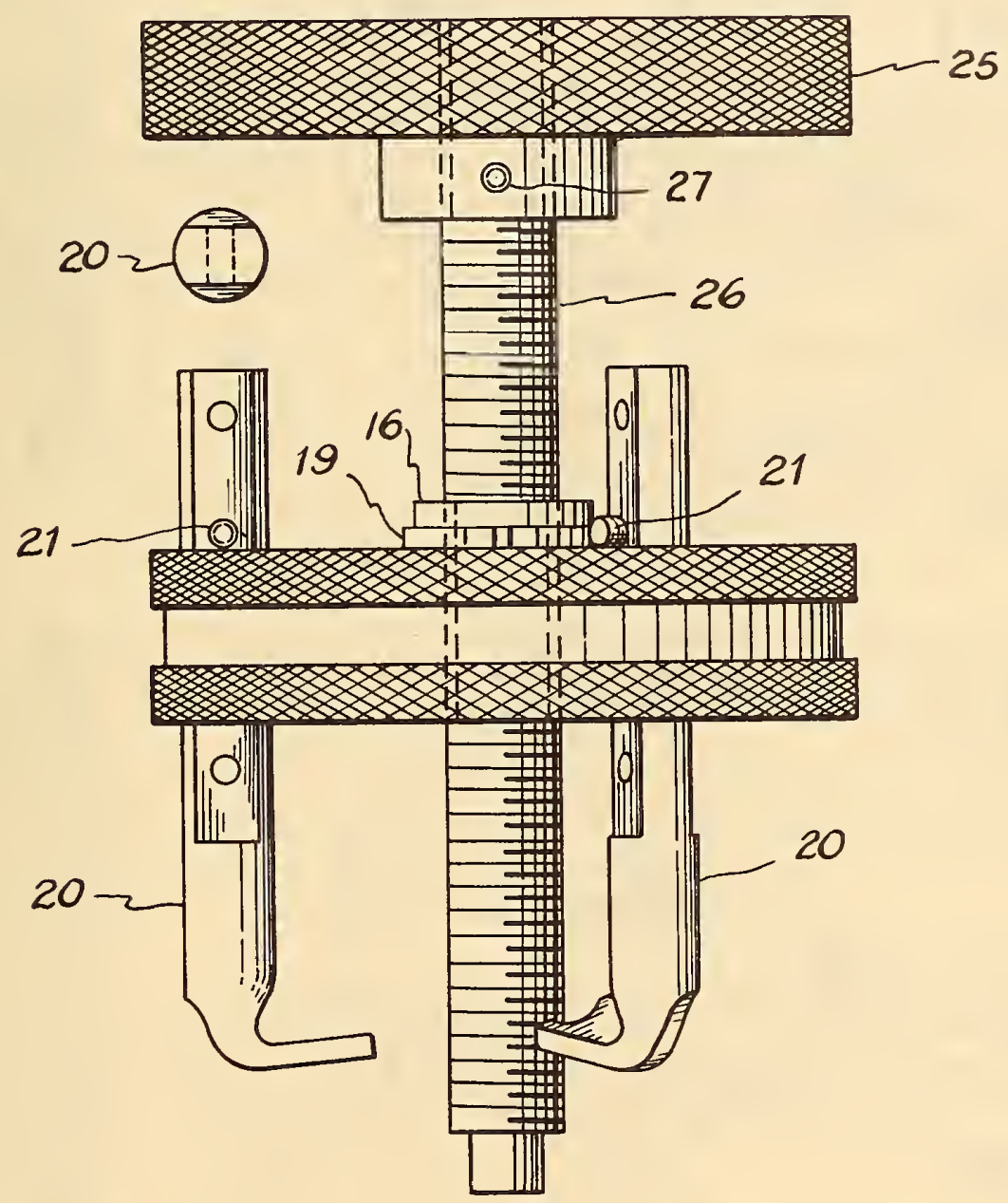

Tech. Note No. 253, November 30, 1964 
MINIATURE GEAR, FLANGE AND BEARING PULLER

Charles B. Haegele
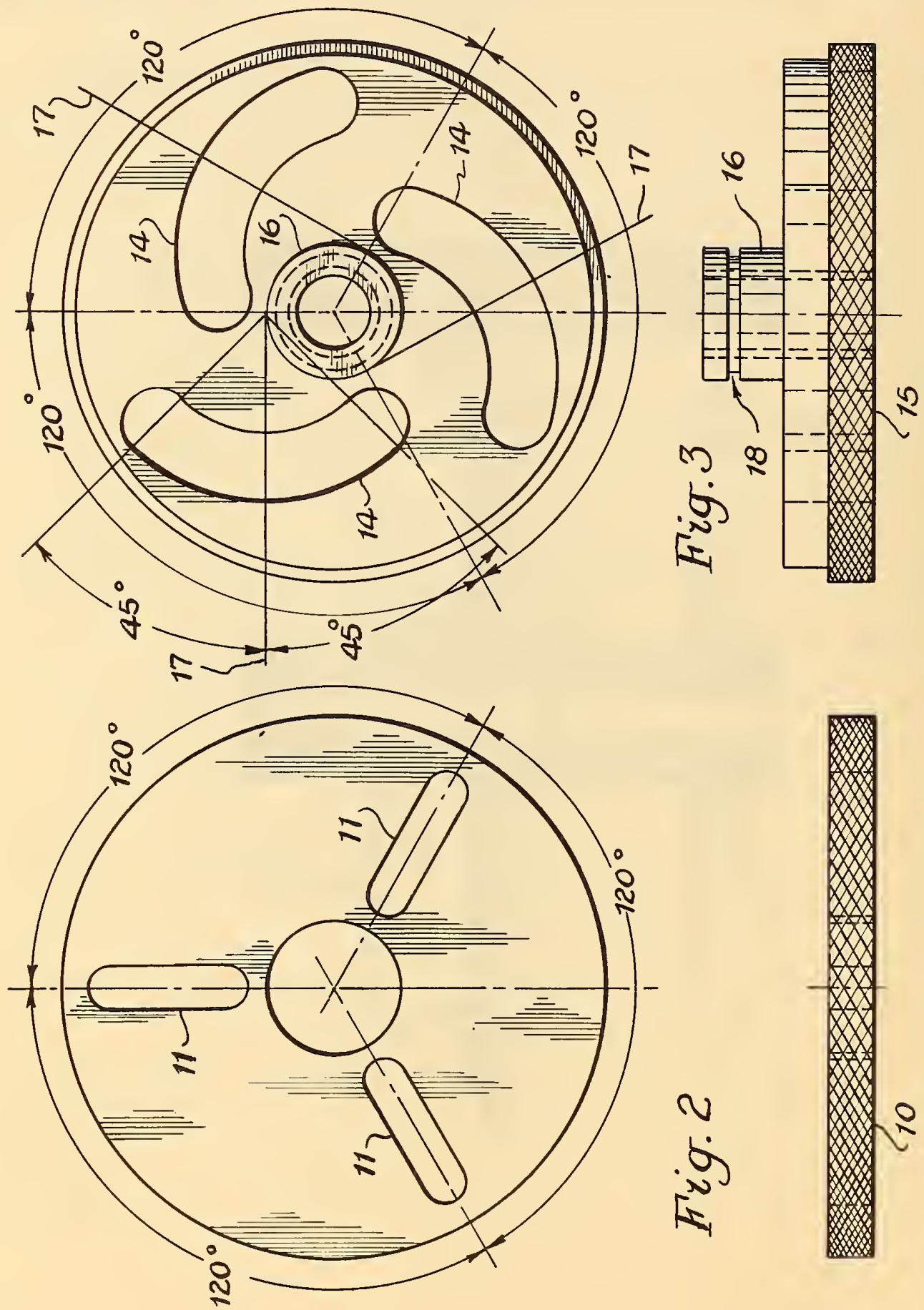

Tech. Note No. 253, November 30, 1964 
Charles B. Haegele

This description relates to a miniature gear, flange and bearing puller that is designed around two basic considerations: adjustable length puller arms and variable range of work diameter.

Fig. 2 shows a knurled disk 10 with straight through slots 11, radiating outward $120^{\circ}$ apart. The slots serve as puller arm guides.

The straight through curved slots 14 in disk 15 (Fig. 3) are made with equal radil whose centers 18 are located $120^{\circ}$ apart on a common circle that is concentric with the outer diameter of hub 16. Each line 17 is tangent to the common circle at one of the centers 18 and is a bisector of a curved slot 14, which extends $45^{\circ}$, on elther side of the line, as shown for one of the slots in Fig. 3 .

The puller arms 20 (Fig. 1) are made of cylindrical stock that is milled flat for a fixed distance on opposite sides of the stock. The flat sides are fitted for free movement in slots 11 (Fig. 2) and the cylindrical surfaces are fitted for free movement in the curved slots 14 (Fig. 3).

Disk 10 is positioned over hub 16 of disk 15 and the two disks are held together by a lock ring 19 (Fig. 1) that fits in slot 18 (Fig. 3). The disks are rotated in opposite directions until each curved slot 14 is under a radiating slot 11 . A puller arm 20 is then inserted through each opening. The desired length of each arm is set and pins 21 are inserted. Knurled knob 25 is then positioned on thrust screw 26 and fastened by means of a roll pin 27 , and screw 26 is inserted into the threaded hub 16.

As disk 15 is rotated, the resultant force exerted by either the inner or outer surfaces of the circular slots 14 against the cylindrical surfaces of puller arms 20 moves each arm an equal distance away from or toward the center of the disks, depending upon the direction of rotation of disk 15. 
U.S. DEPARTMENT OF COMMERCE

WASHINGTON. D.C. 20230

OFFICIAL BUSINESS

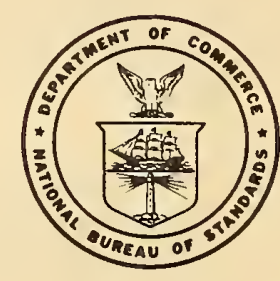

